much interest and includes a summary of the nomenelature which is used consistently throughout the book. Part $I$ is concerned with the derivation of the equations. Both macroscopic and microscopic approaches to the problem are described in successive chapters, special attention being directed in two following chapters to the discussion of absorption.

The equations obtained are complex, and Part 2 is devoted to a detailed discussion of this interpretation. A gradual approach to the most-general case is skilfully employed so that the maximum insight into the significance of the different contributory effects can be obtained. The successive chapters deal with the graphical representation when there are no collisions, the polarization of the waves, the quasilongitudinal and quasi-transverse approximations, the effect of collisions on the indices, some representative curves of the indices, and the group velocity.

A similar gradual approach is used in Part 3, which deals with applications to the Earth's ionosphere. Thus Chapter 12 deals with a model ionosphere with no magnetic field, to be followed by one in which the effect of a magnetic field is included. The concluding (hapter of this part gives an interesting account of the nature of the motion of electrons in the ionosphere in the presence of the Earth's magnetic field.

The last part deals with some miscellaneous subjects. Chapter 15 discusses the question of whether the Lorentz term should be included in the expression for the complex refractive index and Chapter 16 examines the effect of the presence of heavy ions. In Chapter 17 the restriction otherwise maintained of dealing with a homogeneous medium is lifted and many new effects which can then arise are discussed. The final chapter compares and contrasts the propagation through the magnetoionic medium with that through an anisotropic medium such as a crystal. An extensive bibliography is provided.

This monograph is a masterly work written by a great expert not only in the subject but also of exposition. It cannot fail to be of great value to all who are interested in the ionosphere and related subjects. Its appearance at a time when new possibilities of research in radio propagation have been opened up through the use of rocket and satellites is most opportune.

H. S. W. MASSEY

\section{PROPOSALS FOR SPACE FLIGHT}

\section{The Exploration of the Solar System}

By Felix Godwin. Pp. $200+10$ plates. (London: Chapman and Hall, Ltd., 1960.) 35s. net.

7 HIS book represents an attempt to outline the probable development of astronautics between now and the year 2100 , with many detailed accounts of possible expeditions, based on the assumption that only currently foreseeable techniques are used. The first topic discussed is the near-Earth assembly orbit, which will serve as the base for space-ships; then the problems of instrumented and manned expeditions to the Moon are reviewed. Next there is a lengthy and detailed plan for the exploration of Venus, followed by a similar one for Mars. The main text ends with a long chapter on further possibilities, such as visits to the outer planets, plasma rockets and interstellar flight. Finally, there are several appendixes, on topics such as rocket propellants, personnel, space warfare and costs, a glossary and a full index.

Although inevitably there is much that is speculative in the book, the factual detail is piled up with such convincing realism that the reader is often persuaded to suspend disbelief. Many authors of books on space flight give the unfortunate impression that to travel enthusiastically is better than to arrive, but Mr. Godwin's expeditions have a clear aim--to make thorough scientific investigations of the planets -and travelling is merely the means to an end. The author writes in the present tense, as if all the complex operations he describes were matters of routine, and for him there is no gap between the possible and the practical. This might be thought a fault, and attributed to his youth-for he wrote the book between the ages of sixteen and eighteen. But in a book about the future, there would seem to be no harm in recognizing the truth that the technological impossibilities of one generation are the commonplaces of the next. It must be emphasized, too, that the author has voluntarily limited himself to foreseeable techniques: with the development of unforeseen ones, his plans may come to seem timid rather than over-ambitious.

Mr. Godwin evidently has a wide knowledge of most aspects of space technology and physics, but there are plenty of flaws to be found among the crowded detail of the book. His schemes, though ingenious and well thought out, are sometimes out of touch with present practice: for example, solar batteries are not mentioned except in a brief paragraph on p. 124, though power supplies are often discussed earlier. He relies too much on space-flight books of the early 1950's, some of which are now seriously out of date. His use of symbols is undisciplined; for example, the symbol $a$ on pp. 24 and 25 is not only undefined but has two different meanings. Pp. 74-76, explaining in detail the optimum manœuvre for a tanker intercepting a returning space ship, seem to be erroneous: the tanker's weight could be reduced by a factor of about 3 if the transfer were made near perigee. One could go on finding fault in this way, but such flaws do not destroy the book's real merit of providing a logical and well-founded outline of the probable future exploration of the solar system. The reality will, no doubt, be different, but only because of advances not yet predictable.

D. G. KING-HETE

\section{GENERAL AND LINEAR CIRCUIT THEORY}

General Circuit Theory

By Prof. Gordon Newstead. (Methuen's Monographs on Physicel Subjects.) Pp. vii + 144. (London: Methuen and Co., Ltd.; New York: John Wiley and Sons, Inc., 1959.) 15s. net.

rTHIS book is a welcome addition to Methuen's series of monographs on physical subjects. P'rof. Newstead has undertaken the ambitious project of outlining a general circuit theory in 140 small pages and has succeeded to a remarkable extent.

It might have been better to have expanded the book into two volumes, one for steady-state theory and the other for transient theory. Tho author would then have been able to develop his generaliza. 